\title{
1B1075: A Brain- and Pituitary-Specific mRNA that Encodes a Novel Chromogranin/Secretogranin-like Component of Intracellular Vesicles
}

\author{
Hans-Peter Ottiger, ${ }^{1, a}$ Elena F. Battenberg, ${ }^{2}$ Ann-Ping Tsou, ${ }^{1, b}$ Floyd E. Bloom, ${ }^{2}$ and J. Gregor Sutcliffe ${ }^{1}$ \\ Departments of Molecular Biology and ${ }^{2}$ Neuropharmacology, Research Institute of Scripps Clinic, La Jolla, California \\ 92037
}

\begin{abstract}
The rat 1 B1075 mRNA encodes a 533-residue novel chromogranin/secretogranin-like acidic protein that contains an apparent secretion signal, several pairs of tandem basic residues, and internally repeated sequence elements. $1 \mathrm{~B} 1075$ transcripts are detected, by blotting and in situ hybridization, at the highest levels in the neocortex, hippocampus, cerebellar cortex, selected pontine and diencephalic nuclei, and presumptive pituitary corticotrophs, at lower levels in specific nuclei in most other brain regions, but in none of several other tissues. Utilizing antisera to several nonoverlapping synthetic peptide fragments of the predicted protein sequence, we detect a brain- and pituitary-specific 57-kDa protein in cellular processes and fiber tracts, generally consistent with axonal transport from the cell bodies identified by in situ hybridization. Ultrastructural studies demonstrate that this protein is a component of intraneuronal vesicles in axons and vesicle-like structures in dendrites. Based on these data, we suggest the name Secretogranin III for the 1B1075 gene product. In related collaborative studies, a mouse deleted for the 1B1075-homologous gene has been produced that should allow assessment of its physiological role.
\end{abstract}

The vertebrate brain expresses an estimated 30,000 distinct polyadenylated RNAs, probably twice as many as any other tissue (Milner and Sutcliffe, 1983). The diversity of cellular phenotypes in the CNS leads to the quest for molecules that are expressed with some specificity with respect to neuronal cell classes and systems. The application of molecular genetics to the study of mRNAs expressed in the brain is an essential and powerful tool for obtaining knowledge about the structures of the large number of presently unknown brain molecules, which will be required to explain the multiple functions of the CNS.

\footnotetext{
Received Mar. 21, 1990; revised May 4, 1990; accepted May 9, 1990.

We thank Ken Wong and Chris Reilly for exceptional technical assistance, and wc are gratcful for the helpful discussions of P. Staeheli, P. Danielson, M. C. Wilson, J. B. Watson, M. Godbout, and R. Milner. We thank L. Elder for preparation of the manuscript. This work was supported in part by grants from the National Institutes of Health and the Alzheimer's Disease and Related Disorders Association. H.P.O. was supported by a fellowship from the Swiss Foundation for Scientific Research. This is publication 5756-MB from the Research Institute of Scripps Clinic.

Correspondence should be addressed to J. Gregor Sutcliffe, Department of Molecular Biology, Research Institute of Scripps Clinic, 10666 North Torrey Pines Road, La Jolla, CA 92037.

a Present address: Brain Research Institute, August-Forel \#1, CH-8029 Zurich, Switzerland.

b Present address: Syntex Corporation, 3401 Hillview Avenue, Palo Alto, CA 94303.

Copyright (C) 1990 Society for Neuroscience $0270-6474 / 90 / 093135-13 \$ 03.00 / 0$
}

The approach we have taken is to study systematically the mRNAs and proteins that are exclusive to or highly enriched in the mammalian CNS. Such experiments will provide the structures of individual brain mRNAs and proteins, allow the recognition of various patterns of neuronal gene expression, and suggest functions for the previously unrecognized brain proteins. We present here the nucleotide sequence of the rat $1 \mathrm{~B} 1075$ mRNA, whose expression is detected exclusively in neural tissue and the pituitary, and use sequence-specific antibodies to prove the existence of its 57-kDa chromogranin/secretogranin-like putative encoded polypeptide. Ultrastructural studies with the antisera demonstrate that the $1 \mathrm{~B} 1075$ protein is a component of intracellular vesicles.

A mouse strain that is deleted for the murine homologue of this gene has been produced (Kingsley et al., 1990). To be able to conduct informed analyses of the cellular and physiological phenotype of this new mutant, we have carefully examined the neuroanatomical distribution of the 1 B1075 mRNA and its protein product. These data allow us to identify a set of neurons that share the common property of expression of the 1B1075 mRNA and suggest a line of investigation to be followed with the mutant mice to learn the function of the previously unknown $1 \mathrm{~B} 1075$ protein.

\section{Materials and Methods}

Preparation and blotting of RNA. Tissues were isolated by dissection from Sprague-Dawley rats (Charles River Breeding Laboratories, Wilmington, MA) and processed by phenol/chloroform extraction of homogenized tissue (Schibler et al., 1980). RNA was enriched for poly(A)+ by a cycle of oligo(dT)-cellulose (Collaborative Research) chromatography (Aviv and Leder, 1972) in the presence of 1\% SDS. RNA blot analyses were done essentially according to Maniatis et al. (1982).

Construction and screening of a rat brain cDNA library. The initial p1B1075 cDNA clone was used to isolate a full-length clone constructed in the pHG327 vector (Staeheli et al., 1986). Adult rat brain poly(A) ${ }^{+}$ RNA directed first-strand cDNA synthesis with the primer vector fragment and avian myeloblastosis virus reverse transcriptase. After addition of $(\mathrm{dC})$ tails by terminal deoxytransferase, the linker fragment was inserted into the cDNA-RNA hybrids to produce circular molecules. Replacement of the RNA strands with DNA was accomplished by T4 DNA ligase, $E$. coli DNA polymerase, and $E$. coli RNase as described (Okayama and Berg, 1983). The products were used to transform $E$. coli $\mathrm{MC1061}$, and plasmid DNA was isolated from the mass culture and separated on a $0.9 \%$ agarose gel. The plasmids with inserts $>1800$ base pairs (bp) were purified from the gel by phenol extraction and used to transform cells that were screened by colony hybridization (Grunstein and Hogness, 1975) using insert cDNA of plB1075.

Anatomical mapping studies. For in situ hybridization, $20-\mu \mathrm{m}$ cryostat sections were sampled at approximately $400-\mu \mathrm{m}$ intervals from 3 separate rat brains, 2 sectioned in the sagittal plane and 1 sectioned coronally. For immunocytochemistry, $40-\mu \mathrm{m}$ sections were analyzed at $200-\mu \mathrm{m}$ intervals from 5 different rats, using both sagittal and coronal 
Figure 1. Nucleotide sequence of p1 B 1075 and predicted amino acid sequence (single letter code). Putative poly(A) addition signals for the shorter (position 1883) and longer (position 2138) mRNAs are underlined. The predicted signal sequence is indicated in italics; its putative cleavage site is indicated with an arrow. Tandem basic residues are indicated by pluses; the repeated DSTK elements are indicated by dots. The peptides used to elicit antisera are boxed.

planes. Sections were analyzed and evaluated against an extensive checklist (more than 400 structures) of hierarchically organized locations of the rat brain based on the atlas of Paxinos and Watson (1986) and described in detail elsewhere (Bloom, 1989).

In situ hybridization. In situ hybridization was performed according to the protocol of Higgins and Wilson (1987), as recently described (Forss-Petter et al., 1989). ${ }^{35}$ S-NTP-labeled antisense- or control-senseRNA probes were prepared by standard procedures (Melton et al., 1984), using SP6 RNA polymerase to generate the antisense probe and T7 RNA polymerase to generate the control-sense probe from a p1B1075 subclone in the pGEM4 vector.

Peptide-directed antisera. Synthetic peptides $(5 \mathrm{mg})$ corresponding to regions of the $1 \mathrm{~B} 1075$ amino acid sequence were coupled to $5 \mathrm{mg}$ of the carrier protein edestin by incubation at $25^{\circ} \mathrm{C}$ for $30 \mathrm{~min}$ with $0.1 \%$ glutaraldehyde and antisera elicited in rabbits as described (Sutcliffe et al., 1983).

Western blotting. Extracts prepared by homogenizing tissues in a buffer consisting of $60 \mathrm{~mm}$ Tris- $\mathrm{HCl}(\mathrm{pH}, 6.8), 2 \% \mathrm{SDS}$, and $5 \% \beta$-mercaptoethanol were boiled $3 \mathrm{~min}$, then centrifuged at $10,000 \times g$ for 6 min. Approximately $10 \mu \mathrm{g}$ protein was fractionated by electrophoresis in $7.5 \%$ polyacrylamide gels containing $0.1 \%$ SDS (Laemmli, 1970). Proteins in the gel were transferred to nitrocellulose and incubated in Blotto (PBS, $0.5 \%$ Triton $\mathrm{X}-100,5 \%$ nonfat dry milk) for $1 \mathrm{hr}$, in rabbit
anti-1B1075 antibodies in Blotto for $2 \mathrm{hr}$, and finally, in alkaline phosphatase-conjugated goat anti-rabbit IgG.

Immunocytochemistry. Forty- $\mu \mathrm{m}$ sections of adult rat brain, prepared as described (Bloom and Battenberg, 1983), were incubated overnight in a fresh solution of PBS containing 1\% BSA and $<1: 1000$ dilution of antisera at $4^{\circ} \mathrm{C}$. The sections were then washed 3 times for $15 \mathrm{~min}$ each in cold PBS and processed. The primary rabbit polyclonal antibodies were detected on the tissue sections by a commercial avidin-biotin complex (Vecta Stain ABC, Vector Labs, Burlingame, CA), with horseradish peroxidase as the marker and diaminobenzidine as the chromophore. After completion of incubations and washes, sections were briefly exposed to $0.1 \% \mathrm{OsO}_{4}$ and counterstained to enhance cellular nucleic acids. Preparation of samples for electron microscopy was as described (Bloom et al., 1985).

\section{Results}

Cloning and sequence analysis

We used the screen described by Milner and Sutcliffe (1983) to identify cDNA clones from a rat brain library that hybridized on Northern blots to mRNAs expressed in the brain that were not detectable in the liver or kidney. p1B1075 was one such 


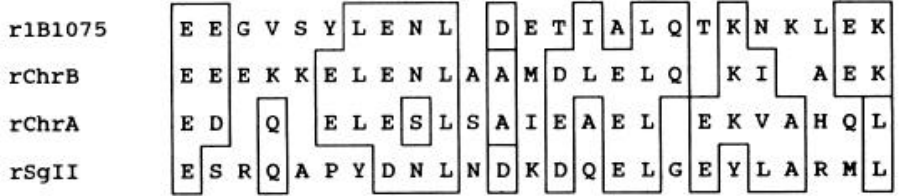

Figure 2. Similarity with chromogranin/secretogranin motif. The region of sequence conserved between human chromogranins/secretogranins (Gerdes et al., 1989) has been expanded, and the rat homologue sequences are compared here: r1B1075 (residues 369-392; this work), rChrB (chromogranin B residues 628-650; Forss-Petter et al., 1989), rChrA (chromogranin A residues 421-442; Iacangelo et al., 1988), and rSgII (secretogranin II residues 460-484; Gerdes et al., 1988). Identical and similar amino acids are boxed. Gaps have been introduced to optimize the alignments.

clone that hybridized to a major brain target of 2.2 kilobases (kb) and a minor (about 5-fold less abundant) brain target of $1.9 \mathrm{~kb}$. We isolated apparently full-length clones of both mRNAs by colony hybridization of the p1B1075 insert to a plated aliquot of an Okayama-Berg-type adult rat brain cDNA library. Their nucleotide sequences (Fig. 1) were determined by the method of Maxam and Gilbert (1977) from both strands over the entire cDNA clones. The longer cDNA consists of 2157 bp and terminates at the $3^{\prime}$ end with a poly(A) tract, preceded by a putative polyadenylation signal AATAAA (position 2138). The shorter clone has a sequence identical to residues 1-1892 of the longer sequence; a putative polyadenylation sequence CATAAA appears at position 1883 . Analysis of the potential reading frames of the 2 1B1075 sequences revealed a single common, long, open-reading frame of 1599 nucleotides beginning with an ATG at nucleotide 178. This frame encodes a polypeptide of 533 residues (conceptually translated in Fig. 1) with a calculated molecular weight of 59,556 Da.

The putative initiator methionine precedes a predominantly hydrophobic 27 -amino-acid region that highly resembles a signal sequence (Perlman and Halvorson, 1983; VonHeijne, 1986). If these $27 \mathrm{~N}$-terminal amino acids are absent from the mature 1B1075 protein, a 507-amino-acid polypeptide chain having a calculated $M_{\mathrm{r}}$ of $56,727 \mathrm{Da}$ remains. Of these 507 residues, 94 are acidic, and 85 are basic. Ten sets of tandem basic residues appear. There are no substantial uncharged regions for membrane spanning or association. The deduced protein sequence has 5 potential sites for $\mathrm{N}$-linked oligosaccharides (Asn-X-Ser/ Thr). However, biochemical evidence (discussed below) shows that $1 \mathrm{~B} 1075$ is not an N-linked glycoprotein.

The 1B1075 polypeptide sequence was searched by computer against the Protein Identification Resource (PIR, March 31, 1988) data base. No significant global sequence identities were found in the search. However, we did notice considerable general similarity with members of the chromogranin/secretogranin family: a signal peptide, an extremely hydrophilic and acidic composition, and a large number of tandem basic residues. Figure 2 illustrates one region of the $1 \mathrm{~B} 1075$ sequence that shows considerable identity with a previously recognized conserved region (Gerdes et al., 1989) of chromogranin/secretogranin molecules. This similarity led us to hypothesize that $1 \mathrm{~B} 1075$ is a new member of the chromogranin/secretogranin protein family, a hypothesis for which we present preliminary support below. An unrelated short sequence (DSTK) is repeated 4 times at positions $156-159,168-171,414-417$, and $432-435$. The region surrounding the 156-159 repeat exhibits a high degree of amino

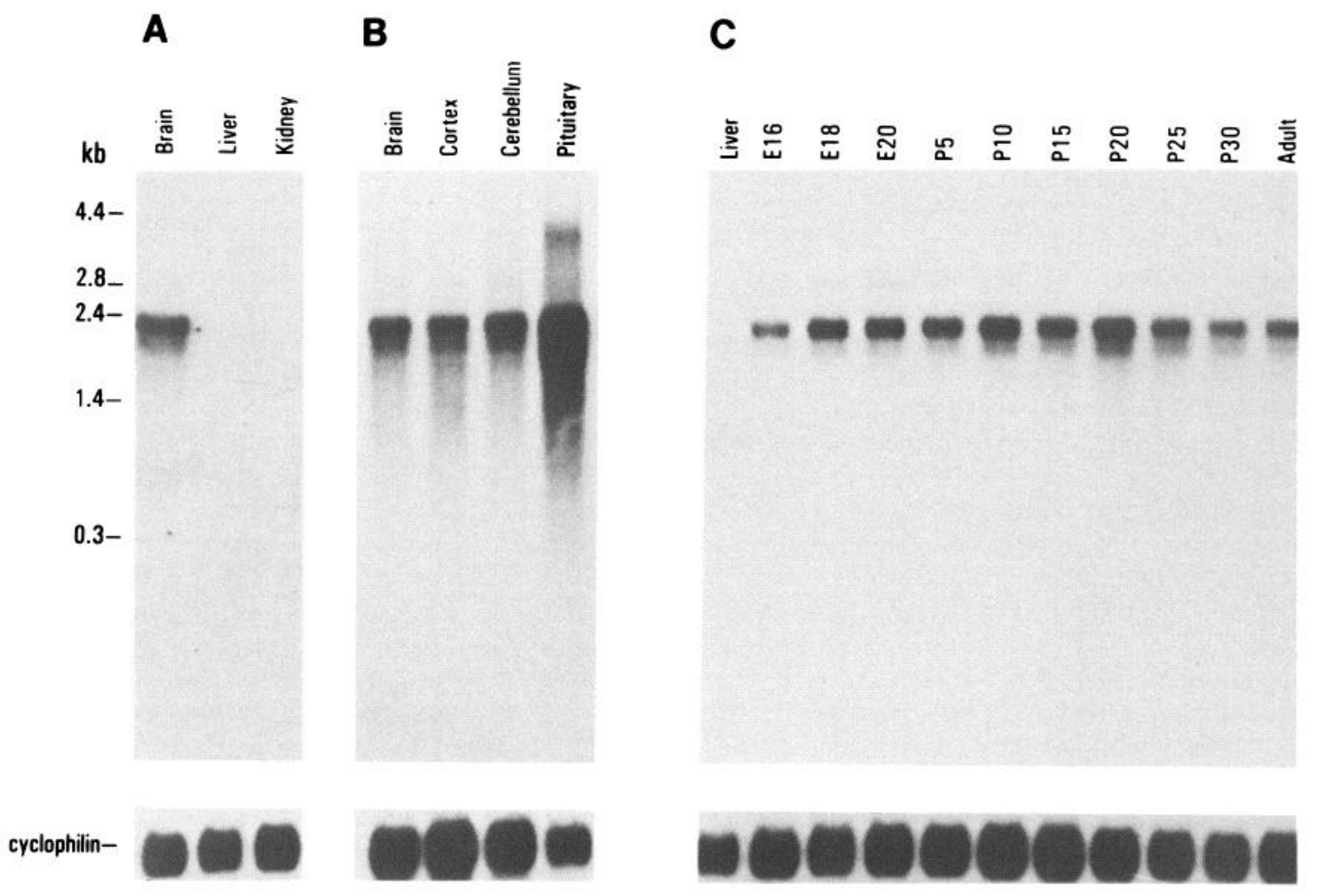

Figure 3. Detection of $1 \mathrm{~B} 1075$ mRNAs. Aliquots of poly(A)+ RNA were prepared for Northern blotting and hybridized (A-C) with ${ }^{32} \mathrm{P}-\mathrm{labeled}$ insert from p1B1075 or, as a control, a clone of the ubiquitously expressed cyclophilin mRNA (Danielson et al., 1988). The pituitary sample in $B$ is from the anterior pituitary. Embryonic days 16-20 (E16-E20) and postnatal days 5-30 (P5-P30), are shown in $C$. 


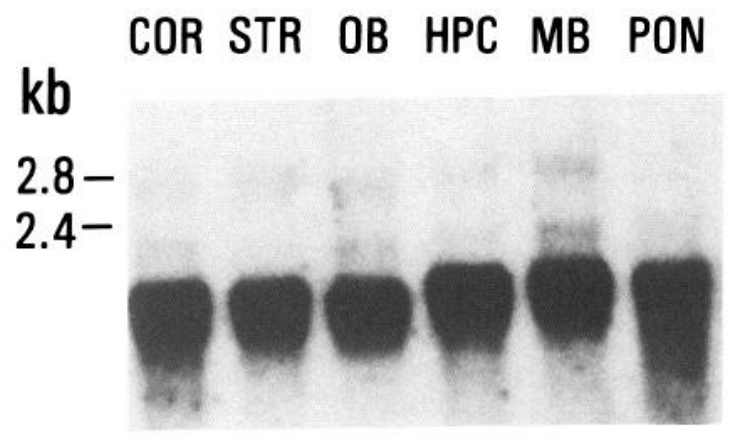

cyclophilin-

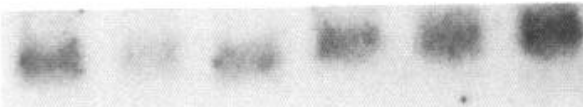

Figure 4. Detection of 1B1075 mRNAs in regions of brain. Samples were prepared and analyzed as in Figure 3. COR, cortex; STR, striatum; $O B$, olfactory bulb; $H P C$, hippocampus; $M B$, midbrain and diencephalon; $P O N$, pons.

acid sequence identity ( $8 / 10$ residues) to a region of viral HIV polymerase (Ratner et al., 1985).

\section{Tissue and developmental mRNA expression}

We used Northern blot analysis to examine the levels of expression of $1 \mathrm{~B} 1075$ mRNAs in cytoplasmic poly(A)+ RNA isolated from several adult rat tissues. We detected (Fig. $3 A$ ) strong hybridization to a 2.2-kb band, and weaker hybridization to a 1.9-kb target, in the brain RNA sample, but we did not detect a signal in samples from the liver or kidney (Fig. 3) or from the lungs, heart, spleen, thymus, adrenal glands, ovaries, or testes (not shown). We estimate, based on the intensity of the hybridization signals, that the $1 \mathrm{~B} 1075 \mathrm{mRNAs}$ represent approximately $0.05 \%$ of adult brain poly $(\mathrm{A})^{+}$RNA.

The $1 \mathrm{~B} 1075$ mRNAs were found, in poly(A)+ RNA isolated from the striatum, olfactory bulb, hippocampus, midbrain, pons, and cerebellum, to be expressed approximately equally in all regions of the brain and in the pituitary at a few-fold-higher level (Figs. 3B, 4). We detected hybridization of the $1 \mathrm{~B} 1075$ probe to mRNAs of identical mobilities as the rat mRNAs in samples from mouse brain, but not mouse liver, and in mRNA from $\mathrm{PC12}$, but not from baby rat kidney, normal rat kidney, C6 glioma, Ltk, NIH3T3, SSLC, or baby hamster kidney cells (not shown).

To examine the time course of the expression of $1 \mathrm{~B} 1075$ mRNAs in the brains of developing rats, we isolated cytoplasmic poly(A) ${ }^{+}$RNA from animals of various ages. The 1 B1075 mRNAs were present at low levels in day-16 embryos, and there was a progressive increase to the highest levels between postnatal days $10-20$ and a decrease thereafter (Fig. $3 \mathrm{C}$ ). Southern blot analyses with rat and mouse genomic DNA (data not shown) are consistent with there being a single 1B1075 gene in each species.

\section{Cellular localization of $1 B 1075$ mRNA}

Although its regional representation in the brain and pituitary as determined by Northern blot analysis was unremarkable, in situ hybridization mapping studies showed that large neurons of cortical and subcortical areas were intensely labeled. We mapped 3 relative levels of hybridization grain density: densely labeled, moderately labeled, and lightly labeled (Fig. 5; compiled in Table 1).

Densely labeled structures were observed in specific largeneuron layers in the hippocampal formation and frontal and parietal cortex, including cells that had the apparent shape characteristics and laminar distributions of hippocampal and neocortical pyramidal neurons. In the frontal and cingulate cortex, labeling was much denser anteriorly and dorsally. In the hippocampus, pyramidal neurons in CA4 and CA3 subfields were most marked, as were subsets of dentate granule neurons (Fig. $5 C$ ). In the cerebellar cortex (Fig. 5A), Purkinje cells were uniformly and intensely labeled, as were individual neurons in all 3 deep cerebellar nuclei. In addition, several specific medullary (Fig. 5E), pontine, and diencephalic (see Table 1) noncortical sites exhibited an equivalent density of grains. Dense labeling was also observed over approximately $20 \%$ of cells in the anterior pituitary. All cells in the intermediate pituitary showed moderate labeling.

Moderately or lightly labeled cells were distributed over subsets of neurons within other nuclei of the thalamus, the septum, the globus pallidus, the substantia innominata, the granule cells of the dentate gyrus, the periventricular zone of the hypothalamus, the third, fifth, and seventh cranial nerve nuclei, and layer III of the piriform cortex (see Table 1). In the lateral deep cerebellar nucleus, approximately $1 / 3$ of the cells showed consistent hybridization. Consistently unlabeled structures included the olfactory tubercle, other subfields of the hippocampus, all major myelinated tracts (except the fimbria, as noted above), other visceral and somatic efferent cranial nerves, other major monoaminergic neuronal nuclei in the pons and medulla, trapezoid and parabrachial nuclei, interpeduncular nucleus, ventral tegmental area, intralaminar thalamic nuclei, the majority of neuronal subnuclei in the amygdaloid complex, and the adrenal gland and lungs. The results are consistent with the overall distribution of the $1 \mathrm{~B} 1075 \mathrm{mRNAs}$ as determined by Northern blotting, but indicate that within particular regions, especially the cerebral cortex, there are particular sets of neurons that are highly enriched for 1B1075 expression.

\section{Detection of the $1 B 1075$ polypeptide}

To demonstrate the existence of the protein encoded by the $1 \mathrm{~B} 1075 \mathrm{mRNAs}$, we used the putative protein sequence to direct chemical synthesis of short fragments of the protein, which were coupled to an immunogenic carrier protein and used to elicit antisera in rabbits. Polyclonal antisera raised against 3 synthetic peptides (Fig. 1, boxes) were used to probe protein transfer blots of homogenates of whole rat brain, liver, and kidney. Each antiserum detected a single immunoreactive protein of $57-\mathrm{kDa}$ mobility in the brain lane, but no comparable species in the liver or kidney lanes (e.g., Fig. 6A). The immunoreactivity of 2 of the antipeptide sera with the target could be blocked by preincubation of the antisera with the appropriate synthetic peptide (e.g., Fig. 6B). No immunoreactivity was detected on immunoblots of whole-brain homogenates probed with the preimmune serum (not shown). These data strongly suggest that the $57-\mathrm{kDa}$, brain-specific target is the product of the 1B1075 mRNA. When brain extracts were incubated with endoglycosidase $F$ prior to gel separation for immunoblotting, no change in the mobility of the immunoreactive species was noted (data not shown), suggesting that none of the potential sites for N-glycosylation observed in the sequence are utilized. 


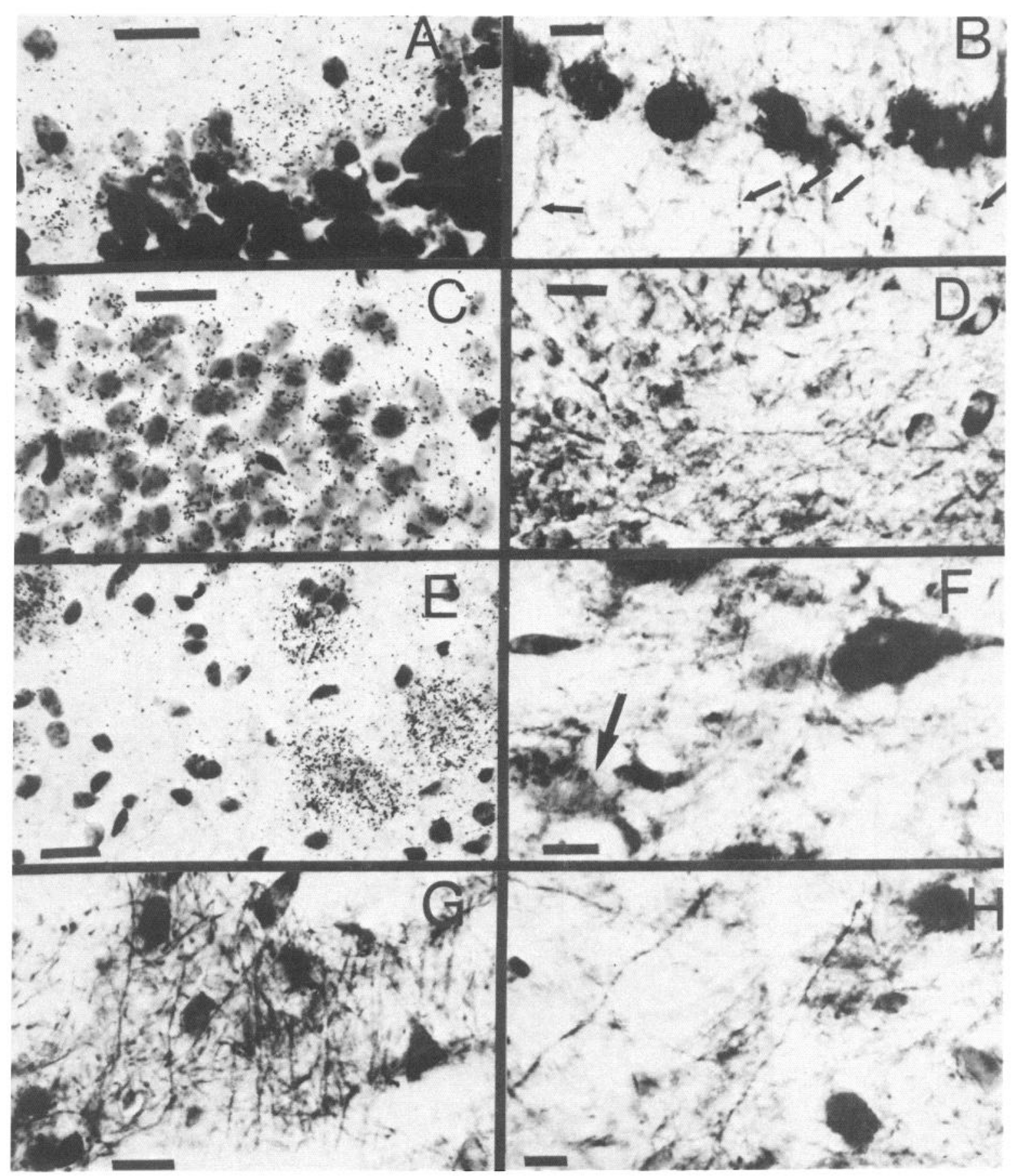

Figure 5. Localization of $1 \mathrm{~B} 1075$ gene products in rat brain by in situ hybridization $(A, C, E)$ and by immunocytochemistry $(B, D, F-H)$. $A$ and $B$, The expression in Purkinje neurons of the cerebellar cortex, with protein immunoreactivity detected both in the apical dendrites and in the axons permeating the unreactive granule cell layer $(B$, arrows). $C$ and $D$, Expression by dentate granule neurons, as well as immunoreactive neurites. $E$ and $F$, Expression of $1 \mathrm{~B} 1075$ within the large neurons of the lateral reticular nucleus of the medulla. At the lower left in $F($ arrow), the granular immunoperoxidase reaction product can be clearly seen in the cytoplasm of a neuron. Immunoreactivity of neurons and their thick, straight neuronal fibers in the globus pallidus is shown in $G$, and more varicose, finer fibers surrounding the subsets of immunoreactive neurons in the medial deep cerebellar nucleus are shown in $H$. Scale bars, $25 \mu \mathrm{m}$ in all fields.

The antipeptide sera detected a single $57-\mathrm{kDa}$ band of similar intensity in extracts from dissected cerebellum, cortex, pons, hippocampus, caudate-putamen, and olfactory bulb (Fig. 6C), and, in extracts from brains of rats at various stages of embryonic and postnatal development, the same $57-\mathrm{kDa}$ species was detected in all samples, but was at lowest concentration in the prenatal samples (Fig. 6D).

\section{$1 B 1075$ protein located in cell processes and fiber tracts}

With the 3 antipeptide sera described above, and additionally with antisera to synthetic peptide fragments corresponding to residues $163-175,207-219$, and 362-374 of the deduced protein sequence, we detect, in immunocytochemistry experiments, immunoreactivity (Figs. 5, 7), in cellular processes and fiber tracts 
Table 1. Distribution of p1 B1075

Immunocytochemistry

In situ hybridization $\quad$ Cells

Fibers

Spinal cord gray matter nuclei/areas

Dorsal gray nuclei

Nucleus proprius (Rexed layers III-VI)

Intermediate gray areas (Rexed layer VII)

Ventral gray nuclei (Rexed layers VIII and IX)

Anterior horn cells (layer IX)

Medulla

Peripeduncular nucleus

External cuneate nucleus

Inferior olive

Dorsal nucleus

Lateral reticular nucleus

Lateral lemniscus, dorsal

Red nucleus

Pons

Trigeminal nerve and nuclei

Spinal tract

Nucleus of spinal tract

Nucleus of mesencephalic tract

Facial nucleus

Dorsal cochlear nucleus

Medial vestibular nucleus

Reticular formation

Gigantocellular tegmental field

Magnocellular tegmental field

Nucleus locus coeruleus

Pontine reticular nucleus

Pontine nuclei

Superior olive

Cerebellum

Lobules

Simple (I-VIII)

Purkinje cell layer

Granule cell layer

Nuclei

Medial (fastigial) nucleus

Interpositus cerebellar nucleus

Lateral cerebellar nucleus

Midbrain

Superior colliculus

Inferior colliculus

Central nucleus

External nucleus

Substantia nigra

Diencephalon

Thalamus

Anterior nuclear group

Anteromedial thalamic nucleus

Medial nuclear group

Midline nuclear group

Paraventricular thalamic nucleus

Ventral nuclear group

Ventroposterior thalamic nucleus

Reticular nucleus of the thalamus

Metathalamus

Medial geniculate nucleus
$\mathrm{N}$

$\mathrm{N}$

0

$++$

0

0

0

$++$

0

$+$

$++$

$++$

$+$

$++$

$+++$

$+t+$

0

$++$

$+t$

$+$

$++$

$++$

$++$

$++$

$+t$

$+++$

0

$++$

$++$

0

0

0

$++$

$++$

$++$

$++$

0

$+$

0

$++$

$+$

$+++$

$+++$

0

$+$

$+$

$+$

0

$++$

$++$

0

$++$

$++$

$+t$

$+t$

$+$

0

$+t+$

$+t$

0

$+$

0

$+t$

$++$

$++$

0

$++$

0

0

$+t$

0

$+++$

$++$

0

$++$

$+t$

0

0

0

$++$

$++$

0

0

$++$

$+$

$++$

$++$

$+1-$

$+1-$

0 


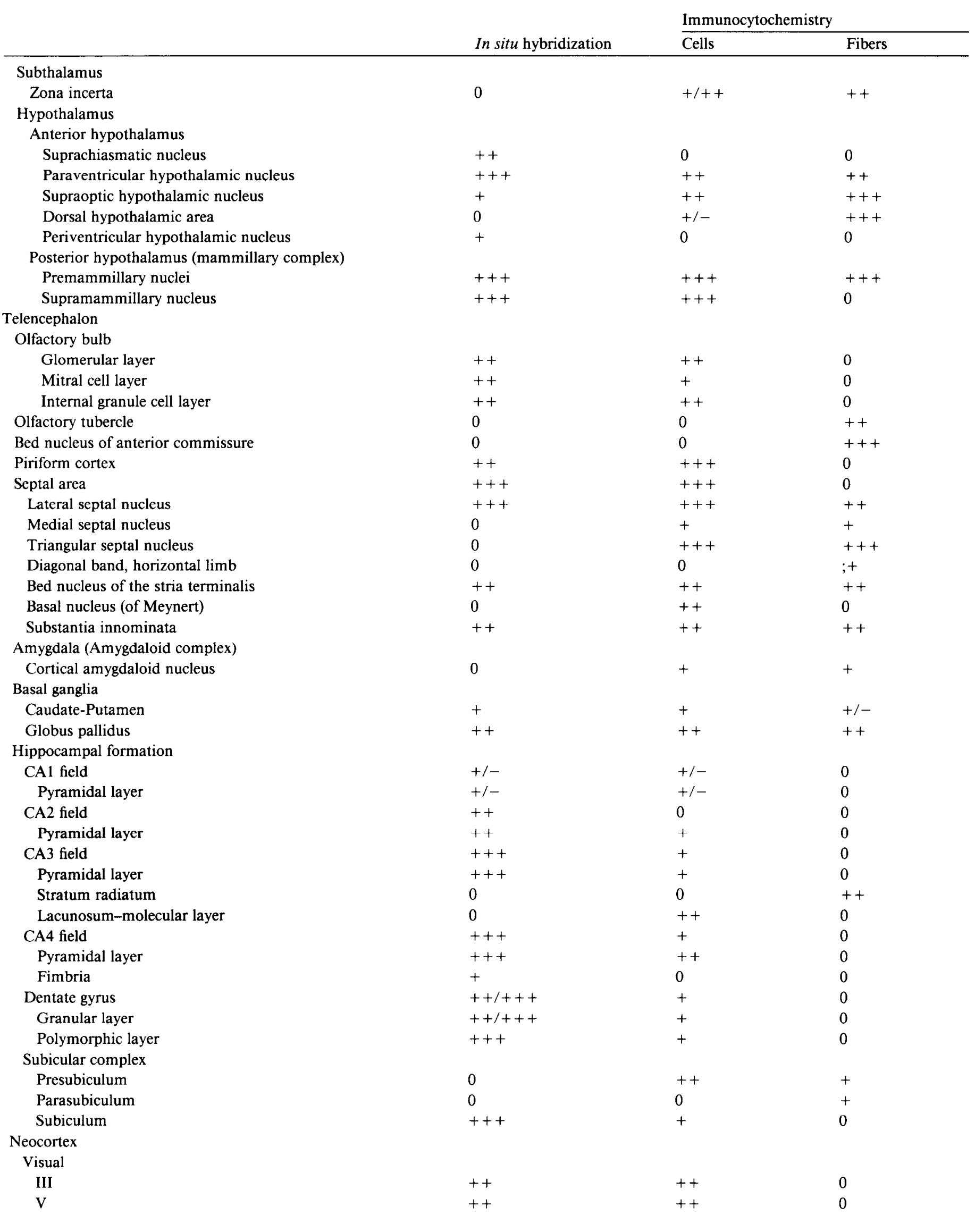


Table 1. Continued

\begin{tabular}{|c|c|c|c|}
\hline & \multirow[b]{2}{*}{ In situ hybridization } & \multicolumn{2}{|c|}{ Immunocytochemistry } \\
\hline & & Cells & Fibers \\
\hline \multicolumn{4}{|c|}{ Somatosensory } \\
\hline III & ++ & ++ & 0 \\
\hline IV & 0 & 0 & ++ \\
\hline V & ++ & ++ & 0 \\
\hline WM & 0 & 0 & +++ \\
\hline \multicolumn{4}{|l|}{ Frontal } \\
\hline II & 0 & 0 & ++ \\
\hline III & ++ & ++ & 0 \\
\hline $\mathrm{V}$ & ++ & + & 0 \\
\hline VI & ++ & + & 0 \\
\hline
\end{tabular}

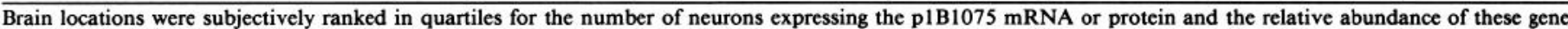

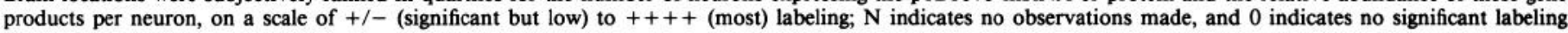
detected.

generally consistent (Table 1) with axonal transport from the cell bodies identified by the in situ hybridization. Because of the natures of the 2 analytic methods, we have made a far more comprehensive analysis of the cellular distributions of the $1 \mathrm{~B} 1075$ immunoreactivity. The following general cellular distributions were observed with all sets of antisera. Immunoreactivity was reduced considerably (but not completely) after overnight absorption of an antiserum to residues 255-267 (animal 7645) with this synthetic peptide $(1 \mu \mathrm{g} / \mathrm{ml})$.

General results. Throughout the rat nervous system, discrete subsets of neurons exhibited combinations of fiber-like, perikaryonal, or dendritic immunoreactivity; no cellular elements identifiable as oligodendrocytes, astrocytes, or vascular or ependymal elements showed reproducible immunoreactivity. Immunoreactivity in neuronal perikarya was generally limited to intracytoplasmic granules within large neurons $(25 \mu \mathrm{m}$ or more in diameter), though some smaller neurons with more diffuse immunoreactivity were also seen. Two other forms of immunoreactivity were identified as fiber-like. One such form included dendritic structures seen in direct extension from perikarya with immunoreactive granular reaction products; such structures were generally seen within thick, straight, and occasionally branched structures on the order of 3-10 $\mu \mathrm{m}$ in diameter. The other form consisted of highly branched fibers on the order of 1-3 $\mu \mathrm{m}$ diameter, marked by distinct varicosities. Straight, thick, immunoreactive fiber-like structures observed in regions with no remarkable immunoreactivity within neurons could also suggest "fibers of passage." Such structures, especially prominent in the lateral and deep portions of the cerebral cortex, were confirmed as axonal projection fibers by ultrastructural analysis of the immunoperoxidase reaction product. Within the dendrites and generally thick varicose fibers, immunoreactivity was consistently uniform, with no obvious granular elements detectable.

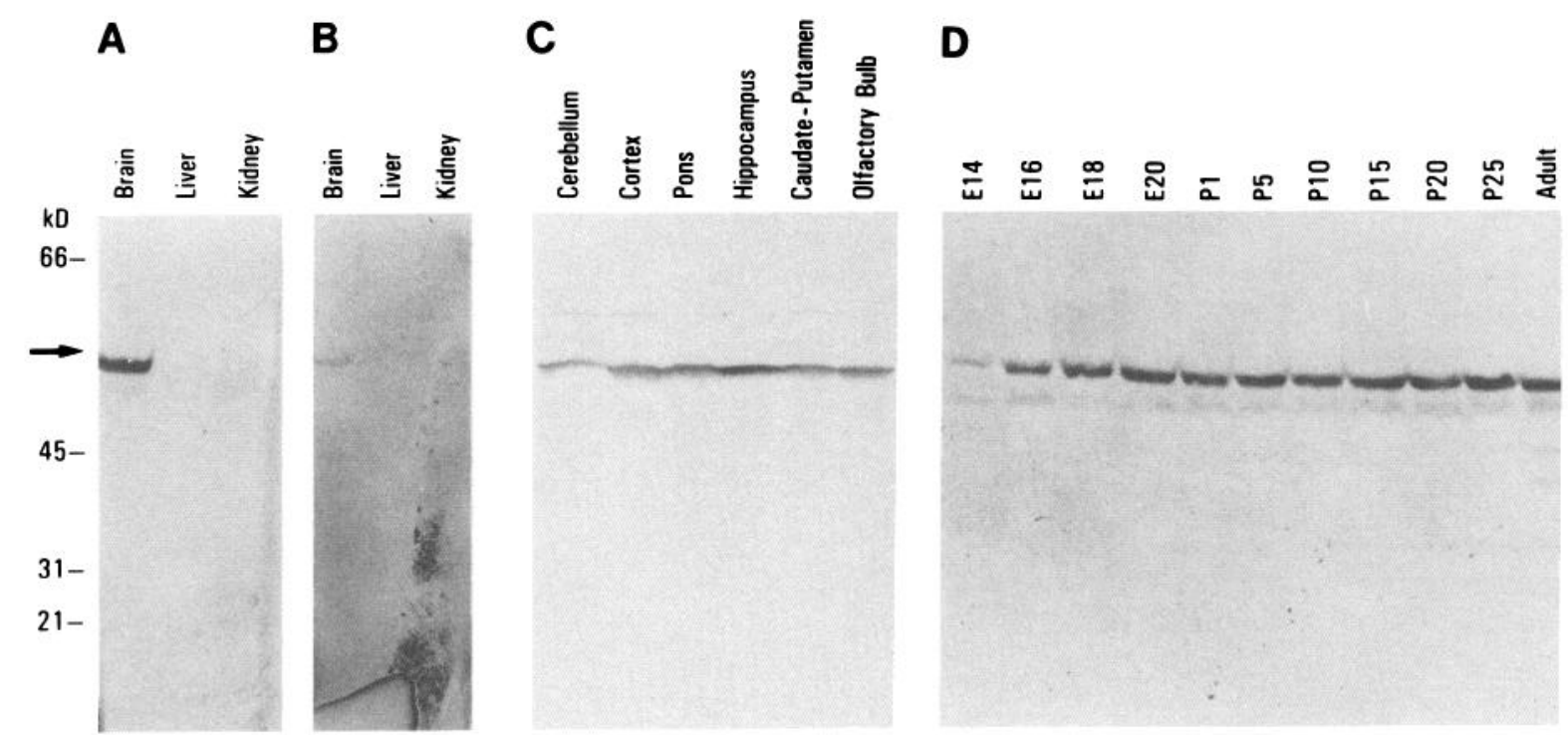

Figure 6. Detection of 1B1075 protein. Extracts from various rat tissues were applied to SDS-PAGE for immunobloting with antipeptide antibodies. $A$ and $D$, Blots reacted with antibody to residues 275-287 from animal 5360. B. Parallel blot reacted with the same serum that had been incubated overnight at $4^{\circ} \mathrm{C}$ with the synthetic peptide $(60 \mu \mathrm{g} / \mathrm{ml})$. C, Blot reacted with antibody to residues 328-340 from animal 727. E14-E20, embryonic days 14-20; P1-P25, postnatal days 1-25. 


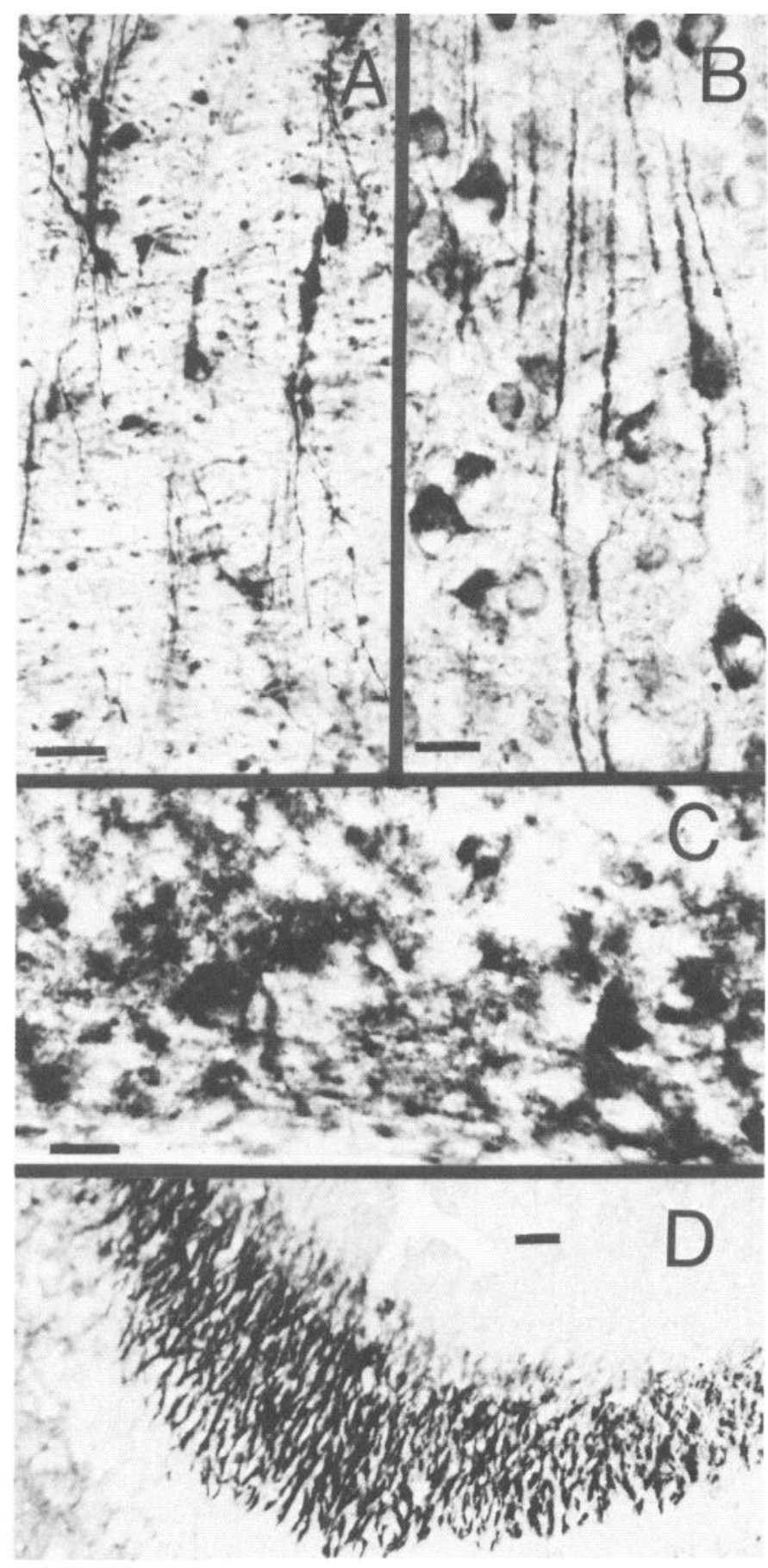

Figure 7. Additional sites of immunoperoxidase-localized expression of 1 B1075 protein. $A$, The fine varicose fibers within the dorsal ascending columns of the spinal cord. $B$, The apical dendrites and neuronal cell bodies of presumptive pyramidal neurons of the deep layers of the neocortex. $C$, A dense band of immunoreactive fine fibers in the superficial layers of the olfactory tubercle. $D$, The striatum lucidum (mossy fiber zone) along apical dendrites of mainly unreactive hippocampal CA3 pyramidal neurons. Scale bars: $25 \mu \mathrm{m}$ for $A-C, 50 \mu \mathrm{m}$ for $D$.

Spinal cord. Throughout the spinal cord, strong immunoreactivity was detected within dense fiber-like structures in the dorsal (Fig. 7A) and ventral gray matter and within the dendrites and axons of the anterior horn neurons (within the perikarya of these cells, only modest, granular immunoreactivity could be

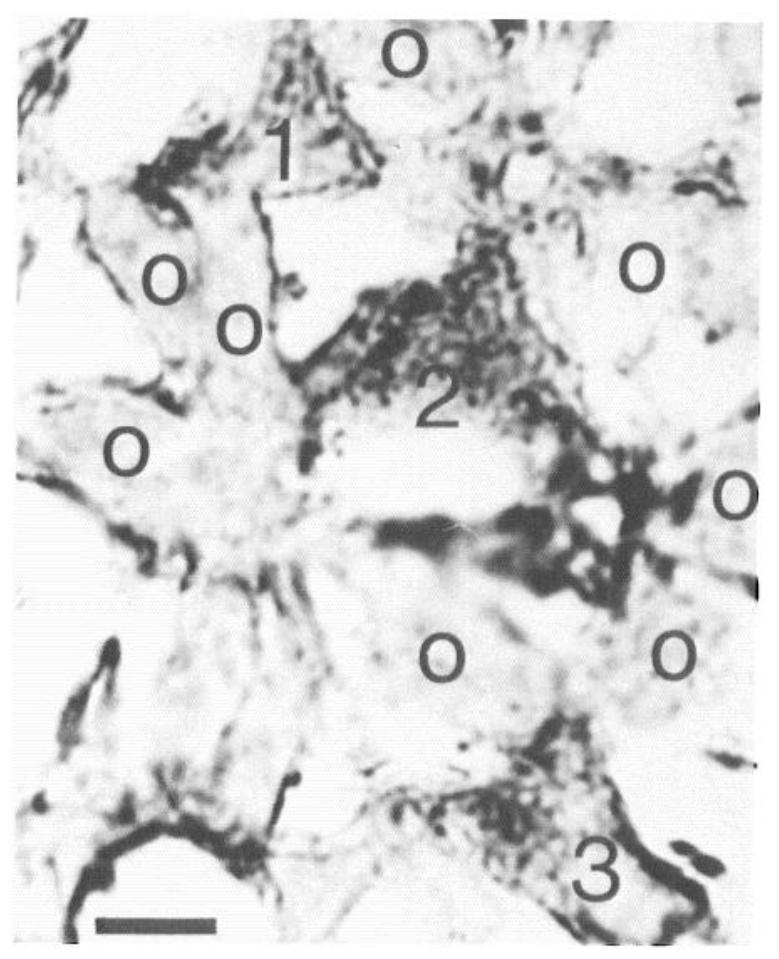

Figure 8. High resolution optical microscopic localization of 1 B 1075 immunoreactivity in selected cells of anterior pituitary. In this $0.5-\mu \mathrm{m}$ thick epoxy section of rat pituitary, dense immunoperoxidase reaction products are visualized within parts of 3 adjacent cells $(1,2,3)$ as small, rounded organelles that fill most of the cells' cytoplasm. These reactive cells are surrounded by multiple cells with no detectable immunoreactivity $(0)$. Scale bar, $0.5 \mu \mathrm{m}$.

observed). Even more extensive immunoreactivity was detected within the neuropil of the nucleus proprius (Rexed layers IIIVI) of the dorsal portion of the cord, with very dense, long varicose fibers extending from the dorsal horn (when immunoreactive neurons were visualized) into the ascending myelinated tracts of the fasciculus gracilis and cuneatus and the ventral spinocerebellar tract. Within the nucleus proprius, a small proportion of neurons were observed with distinctively immunoreactive dendrites and with granular immunoreactive elements within the otherwise lightly reactive perikaryonal cytoplasm. No obvious differences were observed across the segmental levels of the cord.

Hindbrain. Perikaryonal immunoreactivity was intense within the following nuclear sites, listed in roughly descending order of intensity: Purkinje neurons (Fig. $5 B$ ), neurons of the lateral and interpositus deep cerebellar nuclei, the red nucleus, the nucleus of the spinal tract of the trigeminal complex (especially the oral and interpositus subnuclei), the dorsal cochlear nucleus, multiple isolated large neurons of the tegmental medullary reticular formation $\gg$ lateral reticular nucleus (Fig. $5 F$ ) $\gg$ the pontine nucleus, dorsal nucleus of the lateral lemniscus, the inferior olivary complex, and a few neurons in or around the locus coeruleus. In most of these regions, immunoreactive fibers, both thick and varicose, were also observed in approximately similar proportions. However, dense fibers without immunoreactive perikarya were also observed, particularly in the external cuneate nucleus, superior olivary complex, medial vestibular nucleus, and medial (fastigial) deep cerebellar nucleus (Fig. $5 H$ ).

Midbrain. Immunoreactivity within the inferior colliculus was 


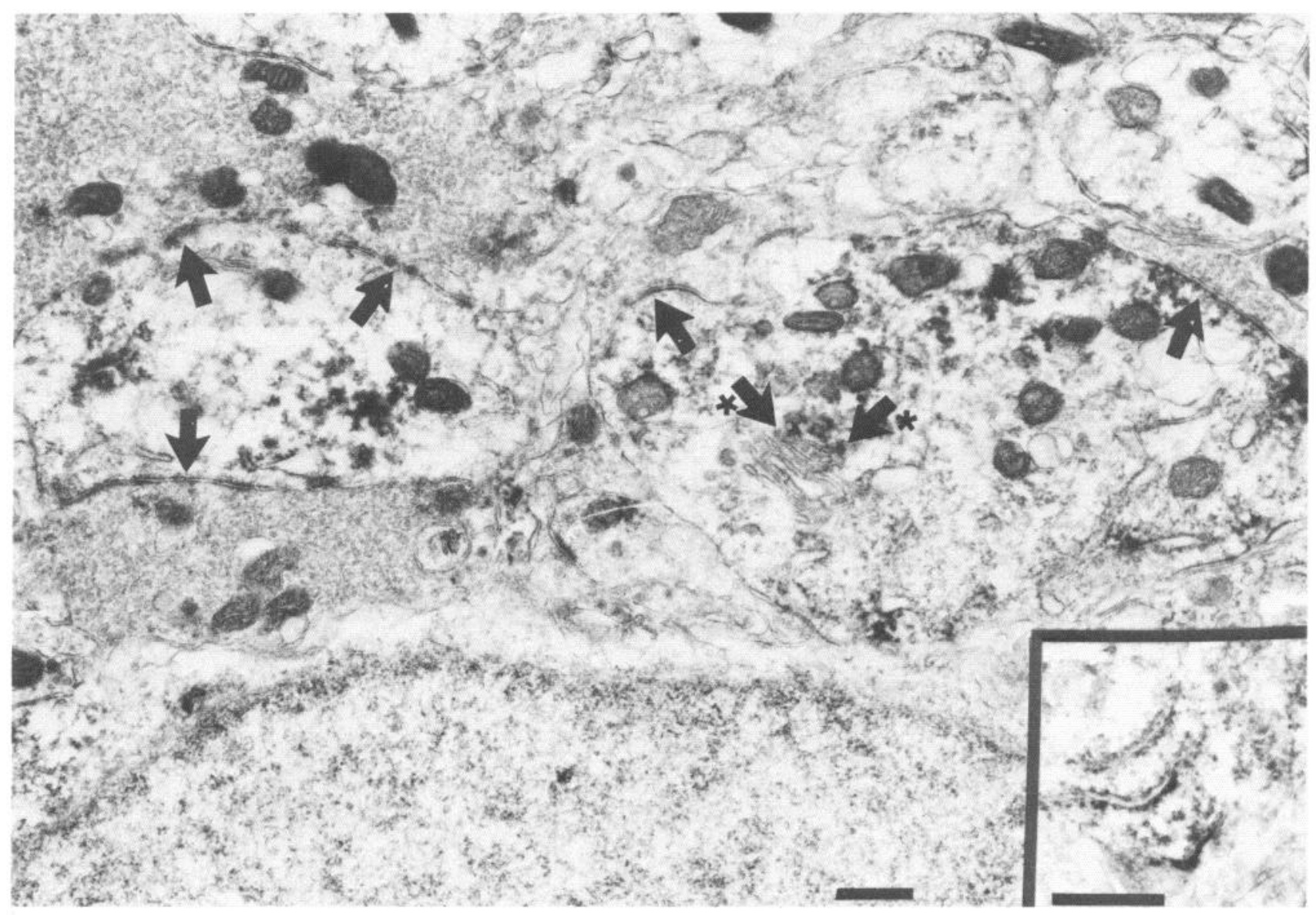

Figure 9. Ultrastructural localization of 1B1075 immunoreactivity in field CA3 of rat hippocampal formation. Two large dendrites of pyramidal neurons are cut horizontally to reveal intradendritic immunoreactivity clustered within groups of small vesicular organelles. Typical mossy fiber terminals, devoid of immunoreactivity, are seen at the perimeter of the immunoreactive dendrites, with some of the specialized contacts indicated by arrows. Immunoreactivity is also seen within one set of cisternae of the Golgi apparatus seen in the dendrite at right (arrow*). An inset at the lower right shows immunoreactivity on the cytoplasmic surface of rough endoplasmic reticulum of a cerebrocortical neuron. Strong, but variable, density in the mitochondria is interpreted as diffusion of the peroxidase product. Scale bar, $0.5 \mu \mathrm{m}$.

far more prominent than in the superior colliculus, with neurons and fibers especially dense within the deep layers and the external nucleus. Cells and fibers with immunoreactivity were also prominent throughout the substantia nigra.

Diencephalon and pituitary. Immunoreactivity was prominent within perikarya of the anterior and midline nuclei of the thalamus, as well as in the ventral posterior nucleus and the reticular nucleus. Occasional neurons in the medial geniculate nucleus were immunoreactive. Within the hypothalamus, immunoreactive neurons were observed in the zona incerta; the paraventricular, supraoptic, premammilary, and supramammilary nuclei; and possibly in the suprachiasmatic nuclei. Fibers without associated immunoreactive perikarya were prominent in the dorsal hypothalamic area.

Related to diencephalic structures, granular immunoreactiv- ity was detected in about $20 \%$ of the cells of the anterior pituitary and less abundantly but more evenly over all cells of the intermediate lobe. Little or no immunoreactivity was detected over axons in the posterior pituitary. To determine the nature of the immunoreactive deposits within cells of the anterior and intermediate lobes of the pituitary, tissues were embedded in epoxy resins after the immunocytochemical procedure and sectioned at $0.5-1.0 \mu \mathrm{m}$ thickness. By both bright-field and phase microscopy, the immunoreactivity appeared to be concentrated in rounded granular deposits of $0.2-0.4-\mu \mathrm{m}$ diameter within the immunoreactive cells of the anterior pituitary (Fig. 8) and in even finer granules at lesser density of immunoreactivity within virtually all cells of the intermediate lobe. Additional ultrastructural studies to elucidate the nature of the immunoreactive organelles and their endocrine cell type are in progress.

Figure 10. Ultrastructural localization of 1 B1075 immunoreactivity in rat cerebral cortex. $A$ and $B$, Peroxidase reaction products in and around small synaptic vesicles in boutons making specialized contacts with small dendritic shafts in layers II and III of the parietal cortex. $C$, Three immunoreactive structures are shown. Bouton 1 contains multiple immunoreactive synaptic vesicles, while the small axon $(a)$ from which it enlarges contains no discernible immunoreactivity. Bouton 2 also contains several immunoreactive synaptic vesicles, which are clustered next to the plasma membrane at points of contact to adjacent small dendritic spines. A larger dendrite (3) contains no immunoreactivity at the point of contact with bouton 2 , but does show immunoreactive vesicular material clustered more distally $\left(\right.$ arrow ${ }^{*}$ ). Scale bar, $0.5 \mu \mathrm{m}$. 


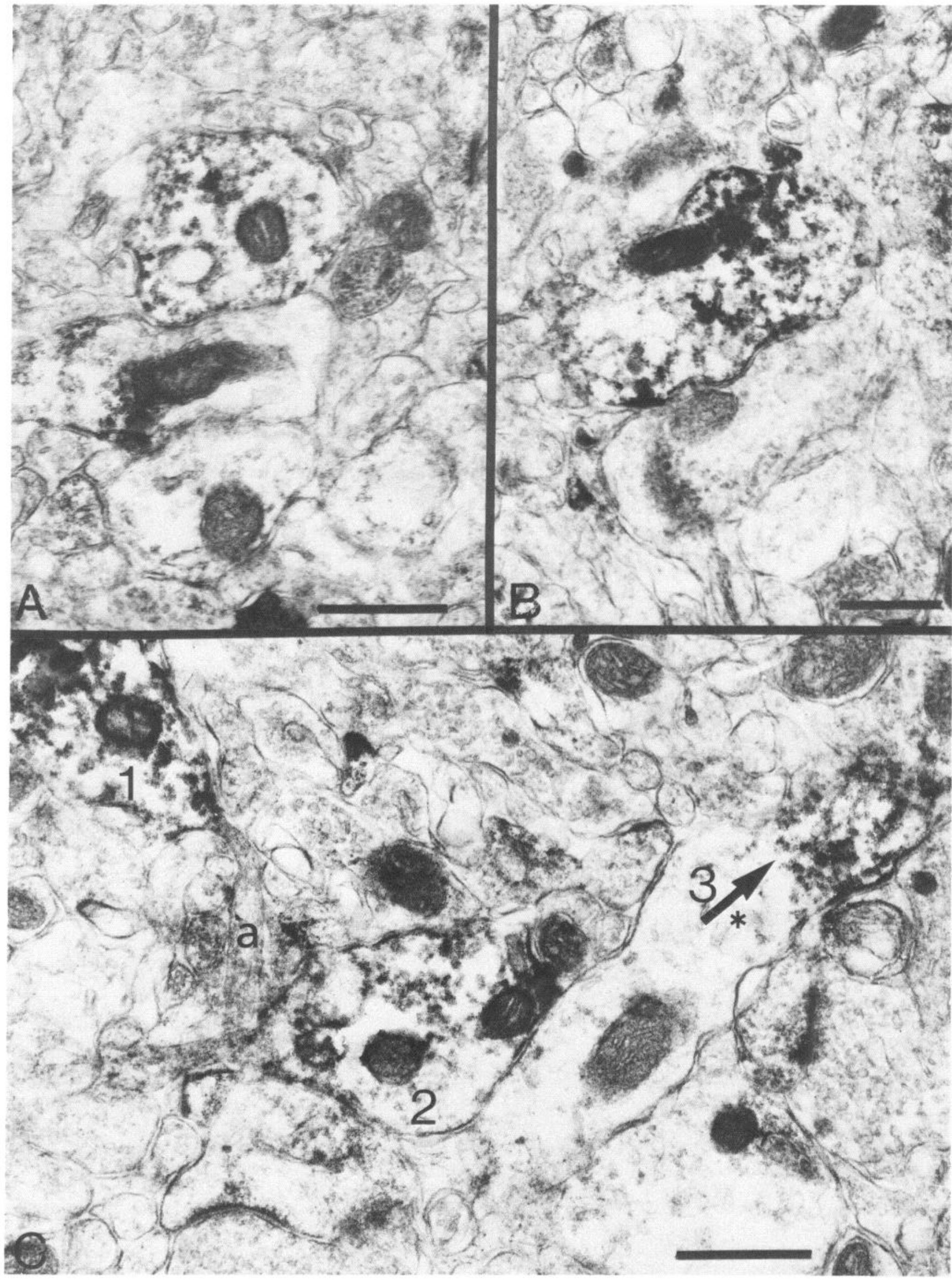


Telencephalon. In the olfactory bulb, periglomerular neurons, as well as a few mitral neurons and their dendrites extending across the external plexiform layer, exhibited immunoreactivity. Dense immunoreactive fibers in the neuropil were observed in the olfactory tubercle (Fig. $7 \mathrm{C}$ ), but not within the neurons of this region. Immunorcactive neurons without surrounding fibers were observed in the nucleus of the lateral olfactory tract, while dense immunoreactive fibers without associated neurons were found surrounding the anterior commissure and were joined with more prominent immunoreactive neurons in the vicinity of the bed nucleus of the stria terminalis. Immunoreactive neurons were detected in the dorsal portion of the lateral septal nucleus, the triangular septal nucleus, and the substantia innominata and in smaller numbers in the medial septal nucleus and cortical nucleus of the amygdaloid complex. Within the basal ganglia (Fig. $5 G$ ), immunoreactivity in the globus pallidus was more prominent than in the caudate-putamen, with cells and fibers predominating in the former, and with less-intense fiber staining and widely separated large-to-medium-sized neurons exhibiting immunoreactivity in the latter structure.

Consistent cellular and fiber immunoreactivity patterns were obscrved within the hippocampal formation, with neuronal immunoreactivity most prominent within the subiculum, and within small subsets of isolated granule neurons in the dentate gyrus (Fig. 5D), within larger neurons in its intrinsic polymorphic layer, within $30-50 \%$ of the CA3 pyramidal neurons, and in the upper layers of the presubiculum and parasubiculum, where a few immunoreactive neurons were detected. Initially, the immunoperoxidase deposits observed throughout the middle and inner thirds of the molecular layer in subfield CA3 (Fig. $7 D$ ) were attributed to mossy fibers. However, given the somewhat limited immunoreactivity of the dentate granule cells from which the mossy fibers are known to arise, this issue was pursued by ultrastructural immunocytochemistry. In contrast to our initial interpretation, immunoreactivity was found to be restricted to small, generally rounded profiles at the perimeter of the major dendrites of the CA3 pyramidal neurons, as well as to the smooth endoplasmic reticulum and Golgi zones of the neurons themselves (Fig. 9). Within the dendrites, immunoreactivity was more prominent in the tertiary and smaller dendritic branches. Often, the immunoreactive elements were immediately subjacent to sites of presynaptic contacts with mossy fiber terminals; however, no mossy fiber immunoreactivity has been observed. Because the small, rounded organelles with immunoreactivity in the dendrites of CA3 pyramidal neurons unexpectedly resembled structures with the size and shape of synaptic vesicles, we reexamined tissues prepared for conventional ultrastructural analysis without immunoperoxidase or other exposures and were able to observe frequent accumulations of clusters of clear, lucent vesicles that resembled the smooth endoplasmic reticulum all along the apical dendrites of these neurons. We conclude that 1 B1075 immunoreactivity is concentrated in small organelles resembling vesicles of smooth endoplasmic reticulum.

Within the neocortex (Fig. 7B), fibers and perikarya were selectively immunoreactive, with immunoreactive perikarya in layers III, V and VI exhibiting long apical dendrities that coursed upwards to layer I. In the frontal cortex, immunoreactive perikarya were found within layers II and III, while in the visual and sensory motor cortical areas, immunoreactive cells with prominent apical dendrites were observed mainly in layers III and $\mathrm{V}$; in the coronal sections of the parietal area, near the border of the neuropil and underlying white matter, favorable sections revealed prominent collections of what appeared to be thick axons coursing into the internal capsule from the overlying cortical mantle.

\section{Immunoreactlvity in intraneuronal vesicles}

By ultrastructural analysis, the immunoreactive elements in the cerebral cortex included, in addition to axons in passage, axons with presynaptic boutons near or at specialized synaptic contacts with dendrites (Fig. 10A,B) and, more rarely, dendrites. The axons and presynaptic boutons exhibited immunoreactivity in and around occasional large granular vesicles and the more frequent small synaptic vesicles that were often clustered immediately adjacent to the site of synaptic specialization. We found within the dendrites (presumed, because of their large diameter and multiple branches, to be arising from pyramidal neurons), the immunoreactivity described above for hippocampal neurons, deposited in and around small spherical organelles interpreted as smooth endoplasmic reticulum (Fig. 10C).

\section{Discussion}

p1B1075 was identified from a rat brain library as a clone whose corresponding mRNA exhibited differential expression between brain and non-neural tissues. We have shown that the single rat $1 \mathrm{~B} 1075$ gene gives rise to 2 stable mRNAs, which differ only in their sites of $3^{\prime}$ polyadenylation, that are detectable in all major areas of the brain, as well as in the pituitary, but not in a large number of other tissues. The predicted primary structure of the 1B1075-encoded polypeptide chain consists of 533 amino acids, the first 27 residues of which have the character of a signal peptide. Processing of the signal sequence would leave a hydrophilic polypeptide chain of 507 amino acids $\left(M_{\mathrm{r}}, 56,723\right)$, a value in good agreement with our assessments of the mobility of the $1 \mathrm{~B} 1075$ protein on $\mathrm{NaDodSO}_{4} / \mathrm{PAGE}$ as detected by Western blotting using antisera to 3 nonoverlapping synthetic peptide analogs of the putative sequence.

In general, the results of localizing studies were comparable with strong concordance (Table 1) between the patterns of 1B1075 mRNA expression in neuronal perikarya, as detected by in situ hybridization, and those for $1 \mathrm{~B} 1075$ protein expression, as detected by immunoreactivity with antisera directed at these 3 and 3 additional nonoverlapping 1B1075 peptidic fragments. Based on the locations of these cells, there would seem to be most extensive involvement of neurons participating in auditory, olfactory, and extrapyramidal motor functions, as well as in neurons related to the hypothalamic-pituitary axis. The distribution and density of 1B1075-expressing cells in the anterior and intermediate pituitary is reminiscent of that of proopiomelanocortin (Bloom et al., 1980), suggesting that 1B1075 is expressed in corticotrophs.

Although 1B1075 is distinct from any of the known chromogranins/secretogranins, it bears considerable resemblance to proteins of the chromogranin/secretogranin family: an $\mathrm{N}$-terminal signal peptide, an extremely hydrophilic and acidic composition, a largc numbcr of paired basic residues, similarity with a conserved chromogranin/secretogranin motif, and embryonic appearance and rapid accumulation during the second postnatal week (cf. Forss-Petter et al., 1989). The immunocytochemical findings that the $1 \mathrm{~B} 1075$ protein is located in vesicles within cell processes and fiber tracts are consistent with this notion. If further studies bear out this hypothesized relationship, the 1 B1075 protein should be designated, according to convention (Eiden et al., 1987), as Secretogranin III. Unlike other members 
of the chromogranin/secretogranin family, Secretogranin III has not been detected in the adrenal gland.

The single homologous mouse 1B1075 gene is tightly linked to the dilute locus on chromosome 9 (Blatt et al., 1985). Gene dosage studies (Kingsley et al., 1990) in mice heterozygous for deletions located in the dilute region of chromosome 9 have led to the identification of a pair of deletions, each covering the $1 \mathrm{~B} 1075$ locus, that are balanced for all necessary genes. Therefore, when mice carrying the deletions are mated, viable offspring with no $1 \mathrm{~B} 1075$ gene are produced. These mutant mice are fertile and exhibit neither overt abnormalities of behavior or anatomy nor impairment of movement. The function of the $1 \mathrm{~B} 1075$ polypeptide in the brain and pituitary and its significance to vitality has yet to be determined, though its sites of expression have been elucidated. This information will allow precise evaluation of the 1B1075-deficient model.

\section{References}

Aviv H, Leder P (1972) Purification of biologically active globin messenger RNA by chromatography on oligothymidylic acid-cellulose. Proc Natl Acad Sci USA 69:1408-1412.

Blatt C, Weiner L, Sutcliffe JG, Nesbitt MN, Simon MI (1985) Chromosomal mapping of murine brain-specific genes. Cytogenet Cell Genet 40:583a.

Bloom FE (1989) Databases of brain information. In: Three-dimensional neuroimaging (Toga AW, ed), pp 273-306. New York: Raven.

Bloom FE, Battenberg ELF (1983) Immunocytochemistry of endomorphins and enkephalins. In: Methods in enzymology: neuroendocrine peptides (Conn PM, ed), pp 670-687. New York: Academic.

Bloom FE, Battenberg ELF, Milner RJ, Sutcliffe JG (1985) Immunocytochemical mapping of $1 \mathrm{~B} 236$, a brain-specific neuronal polypeptide deduced from the sequence of a cloned mRNA. J Neurosci 5:1781-1802.

Bloom F, Bayon A, Battenberg E, French E, Koda L, Koob G, Le Moal M, Shoemaker W (1980) Endorphins: developmental, cellular, and behavioral aspects. In: Neural peptides and neuronal communication, (Costa E, Trabucchi M, eds), pp 619-632. New York: Raven.

Danielson PE, Forss-Petter S, Brow MA, Calavetta L, Douglass J, Milner RJ, Sutcliffe JG (1988) p1B15: a cDNA clone of the rat mRNA encoding cyclophilin. DNA 7:261-267.

Eiden LE, Huttner WB, Mallet J, O'Connor DT, Winkler H, Zanini H (1987) A nomenclature proposal for the chromogranin/secretogranin proteins. Neuroscience 21:1019-1021.

Forss-Petter S, Danielson P, Battenberg E, Bloom FE, Sutcliffe JG (1989) Nuclcotide sequence and cellular distribution of rat chromogranin B (secretogranin I) mRNA in the neuroendocrine system. J Mol Neurosci 1:63-75.

Gerdes H-H, Phillips E, Huttner WB (1988) The primary structure of rat secretogranin II deduced from a cDNA sequence. Nucleic Acids Res 16:11811.
Gerdes H-H, Rosa P, Phillips E, Baeuerle PA, Frank R, Argos P, Huttner WB (1989) The primary structure of human secretogranin II, a widespread tyrosine-sulfated secretory granule protein that exhibits low pH- and calcium-induced aggregation. J Biol Chem 264:1200912015.

Grunstein M, Hogness DS (1975) Colony hybridization: a method for the isolation of cloned DNAs that contain a specific gene. Proc Natl Acad Sci USA 72:3961-3966.

Higgins GA, Wilson MC (1987) In situ hybridization: applications to neurobiology (Valentino K, Eberwine J, Barchas J, eds), pp 146-162. New York: Oxford UP.

Iacangelo A, Okayama H, Eiden LE (1988) Primary structure of rat chromogranin A and distribution of its mRNA. FEBS Lett 227:115121.

Kingsley DM, Rinchik EM, Russell LB, Ottiger HP, Sutcliffe JG, Copeland NG, Jenkins NA (1990) Genetic ablation of a mouse gene expressed specifically in brain. EMBO J 9:395-399.

Laemmli UK (1970) Cleavage of structural proteins during the assembly of the head of bacteriophage T4. Nature 227:680-685.

Maniatis T, Fritsch EF, Sambrook J (1982) Molecular cloning: a laboratory manual. Cold Spring Harbor, NY: Cold Spring Harbor I aboratory.

Maxam AM, Gilbert W (1977) A new method of sequencing DNA. Proc Natl Acad Sci USA 74:560-564.

Melton DA, Krieg PA, Rebagliati MR, Maniatis T, Zinn K, Green MR (1984) Efficient in vitro synthesis of biologically active RNA and RNA hybridization probes from plasmids containing a bacteriophage SP6 promoter. Nucleic Acids Res 12:7035-7056.

Milner RJ, Sutcliffe JG (1983) Gene expression in rat brain. Nucleic Acids Res 11:5497-5520.

Paxinos G, Watson C (1986) The rat brain in stereotaxic coordinates. Australia: Academic.

Okayama H, Berg P (1983) A cDNA cloning vector that permits expression of cDNA inserts in mammalian cells. Mol Cell Biol 3: $280-289$.

Perlman D, Halvorson HO (1983) A putative signal peptidase recognition site and sequence in eucaryotic and procaryotic signal peptides. J Mol Biol 167:391-409.

Ratner L, Haseltine W, Patarca R, Livak KJ, Starcich B, Josephs SF, Doran ER, Rafalski JA, Whitehorn EA, Baumeister K, Ivanoff L, Petteway SR Jr, Pearson ML, Lautenberger JA, Papas TS, Ghrayeb J, Chang NT, Gallo RC, Wong-Staal F (1985) Complete nucleotide sequence of the AIDS virus, HTLV-III. Nature 313:277-284.

Schibler K, Tosi M, Pittet A-C, Fabiani L, Wellames P (1980) Tissuespecific expression of mouse $\alpha$-amylase genes. J Mol Biol 142:93116.

Staeheli P, Haller O, Bell W, Lindenmann J, Weissmann C (1986) Mx protein: constitutive expression in 3T3 cells transformed with cDNA confers selective resistance to influenza virus. Cell 44:147-158.

Sutcliffe JG, Milner RJ, Shinnick TM, Bloom FE (1983) Identifying the protein products of brain-specific genes with antibodies to chemically synthesized peptides. Cell 33:671-682.

VonHeijne $G$ (1986) A new method for predicting signal sequence cleavage sites. Nucleic Acids Res 14:4683-4690. 